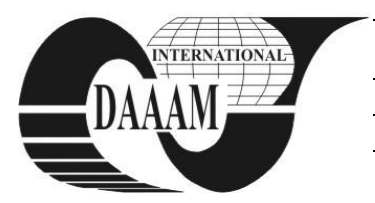

Annals of DAAAM for 2012 \& Proceedings of the 23rd International DAAAM Symposium, Volume 23, No.1, ISSN 2304-1382 ISBN 978-3-901509-91-9, CDROM version, Ed. B. Katalinic, Published by DAAAM International, Vienna, Austria, EU, 2012 Make Harmony between Technology and Nature, and Your Mind will Fly Free as a Bird Annals \& Proceedings of DAAAM International 2012

\title{
MATEMATICAL MODELS OF FORCE AND TORQUE IN DRILLING POLYMERIC BIOCOMPOSITES PRODUCTS
}

\author{
OPRAN, C[onstantin]; DOBRESCU, T[iberiu] G[abriel] \& JIGA, G[heorghe] - G[abriel]
}

\begin{abstract}
For scientific research and industrial application it is important to determine mathematical models of force and torque, when machining. Thus, is would be possible to know optimum process parameters values or even better, to predict force and torque values, once process parameters values set. Drilling in polymeric biocomposites is required in many cases but, unfortunately the existing data published on this topic are very poor and rather qualitative ones. So, a study on polymeric biocomposites material has been done and the results presented by this paper, mainly considering the wide industrial application of this material.
\end{abstract}

Keywords: mathematical model, drilling, force, torque, polymeric biocomposites

\section{INTRODUCTION}

Polymeric bio-composites materials are nowadays widely employed as much for the manufacturing of a lot of daily objects, automotive industry as in the high-tech sector. [2].These materials are well known for the extremely complex behavior strongly depending on the time and the temperature. Some example of natural fiber, figure 1 .

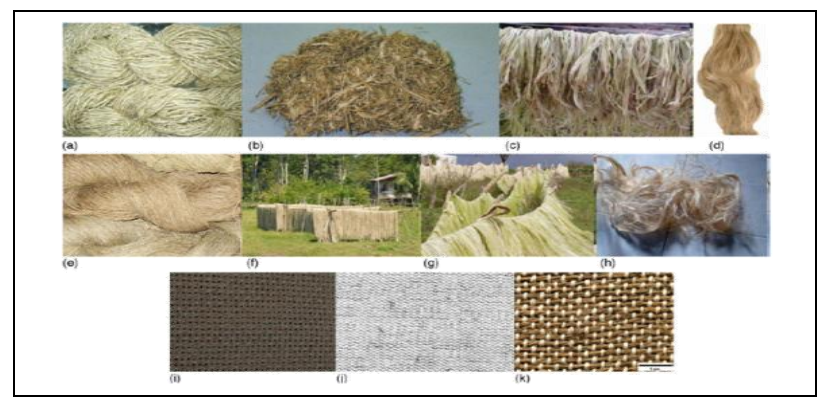

Fig 1. Example of natural fibers

\section{RESEARCH APPLIED METHODS}

Determining mathematical models for the relationship of parameters specific to a certain machining process, based on experimental results, involves some steps to be followed, as the next one [4]:

- the "definition" of both independent and dependent variables associated to these models [1];

- an appropriate experiments design type to be considered;

- the regression analysis, if available;

- the fitted mathematical model to be obtained.

The mathematical models for axial cutting force and torque in drilling polymeric biocomposites materials do look like the ones in relations (1) to (2):

$$
\begin{gathered}
F_{z}=C_{F} \cdot D^{x_{F}} \cdot f^{y_{F}}, \quad[N] \\
M_{z}=C_{M} \cdot D^{x_{M}} \cdot f^{y_{M}},[\mathrm{Nm}]
\end{gathered}
$$

where:

$F_{z}-$ represent the axial cutting force (dependent variable);

$\mathrm{M}_{\mathrm{z}}$ - the torque (dependent variable);

$\mathrm{D}$ - the diameter of the cutting tool, [mm] (independent variable);

$\mathrm{f}$ - the cutting depth of the process [ $\mathrm{mm} / \mathrm{rot}$ ] (independent variable);

$x_{F}, y_{F}, x_{M}, y_{M}-$ polytropic exponents;

$C_{F}, C_{M}$, - constants.

Once the values of $\mathrm{C}_{\mathrm{F}}, \mathrm{C}_{\mathrm{M}}, \mathrm{x}_{\mathrm{F}}, \mathrm{y}_{\mathrm{F}}, \mathrm{x}_{\mathrm{M}}, \mathrm{y}_{\mathrm{M}}$ determined, when further experimenting with same the values for variables $\mathrm{D}$ and $\mathrm{f}$ but, with different values for the cutting speed, vc, there was noticed that different axial force and torque values were obtained.

So, it was assumed that the parameter not mentioned by relations (1) to (2), meaning cutting speed, vc, should have a significant role in axial force and torque values prediction.

In fact, this is the aim of the paper, meaning, presenting the steps followed and, specially, the new mathematical models obtained for the axial force and torque in drilling. The novelty is that it has been considered an important independent variable of the machining process, meaning the cutting speed $v c$ [m/min].

So, the new, original proposed mathematical models are evidenced by relations (3) to (4):

$$
\begin{gathered}
F_{z}=C_{F} \cdot D^{x_{F}} \cdot f^{y_{F}} \cdot v_{c}^{z_{F}} \\
M_{z}=C_{M} \cdot D^{x_{M}} \cdot f^{y_{M}} \cdot v_{c}^{z_{M}}[\mathrm{Nm}]
\end{gathered}
$$

where:

$\mathrm{v}_{\mathrm{c}}$ is the peripheral rotational speed of the cutting tool, usually mentioned as the cutting speed $[\mathrm{m} / \mathrm{min}]$;

$\mathrm{Z}_{\mathrm{F}}, \mathrm{z}_{\mathrm{M}}$ - polytrophic exponents;

For obtaining the constants and polytrophic exponents values, relations (3) to (4) must be of linear type and, so, by logarithm they will "turn" into relations (5) to (6), as follows: 


$$
\begin{aligned}
& \lg F_{z}=\lg C_{F} \cdot \lg D^{x_{F}} \cdot \lg f^{y_{F}} \cdot \lg v_{c}^{z_{F}}, \\
& \lg M_{z}=\lg C_{M} \cdot \lg D^{x_{M}} \cdot \lg f^{y_{M}} \cdot \lg v_{c}^{z_{M}}[\mathrm{Nm}]
\end{aligned}
$$

So, it can be mentioned that the first method, applied was that of solving a four / five linear equations system as there were four / five constants to be determined $(\mathrm{C}$, $\left.x_{F}, y_{F}, z_{F}, x_{M}, y_{M}, z_{M}\right)$, five constants for the drilling process.

The second method applied dealt with experiments design and regression analysis - done with a special software, DOE KISS. [5]

Due to limited license rights (as the authors have only the "student version"), there could only be determined regression models with three independent variables, each of them with two "levels".

So, based on the results obtained by solving relations (5) to (6), for the regression analysis there have been considered the three most "significant" variables - for axial force and torque values.

The three most important variables are: $\mathrm{v}_{\mathrm{c}}, \mathrm{v}_{\mathrm{f}}$ and $\mathrm{a}_{\mathrm{e}}$.

The experiments design (Central Composite Design, CCD) is evidenced in table 1 .

Regression analysis performed by the software resulted in models like the ones mentioned by relations (7) to (8):

$$
\begin{aligned}
& F z=a_{0}+a_{1} \cdot D+a_{2} \cdot f+a_{3} \cdot v_{c}+a_{12} \cdot D \cdot f+ \\
& +a_{13} \cdot D \cdot v_{c}+a_{23} \cdot f \cdot v_{c}+a_{123} \cdot D \cdot f \cdot v_{c} \\
& M z=a_{0}+a_{1} \cdot D+a_{2} \cdot f+ \\
& +a_{3} \cdot v_{c}+a_{12} \cdot D \cdot f+a_{13} \cdot D \cdot v_{c}+ \\
& +a_{23} \cdot f \cdot v_{c}+a_{123} \cdot D \cdot f \cdot v_{c}
\end{aligned}
$$

\begin{tabular}{|c|c|c|c|c|}
\hline \multirow{9}{*}{ 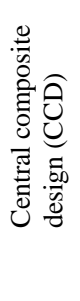 } & Run & $\mathrm{X} 1$ & $\mathrm{X} 2$ & $\mathrm{X} 3$ \\
\hline & 1 & -1 & -1 & -1 \\
\hline & 2 & -1 & -1 & +1 \\
\hline & 3 & -1 & +1 & -1 \\
\hline & 4 & -1 & +1 & +1 \\
\hline & 5 & +1 & -1 & -1 \\
\hline & 6 & +1 & -1 & +1 \\
\hline & 7 & +1 & +1 & -1 \\
\hline & 8 & +1 & +1 & +1 \\
\hline
\end{tabular}

Tab 1. The experiments design

The relationship of "coded" variables, and "natural" ones, $z_{j}$ $\left(\mathrm{z}_{\mathrm{j}}=\mathrm{D}, \mathrm{f}, \mathrm{v}_{\mathrm{c}}\right)$ is $(7)$ :

$$
x_{j}=\frac{z_{j}-\frac{z_{\min }-z_{\max }}{2}}{\frac{z_{\max }-z_{\min }}{2}}
$$

where:

$\mathrm{z}_{\min }$ - is the minimum experimental value;

$\mathrm{z}_{\max }$ - the maximum experimental value.

\section{EXPERIMENTS AND RESULTS}

In order to make experiments, there was designed and used an experimental system, whose main components are the next - see figure 4 and figure 5 . a) CNC machine tool, coded FIRST MCV 300 with characteristics:

- electric motor of 7,5 - $11 \mathrm{~kW}$ power;

- working plateau dimensions of 610 x 305 x 460 (mm x $\mathrm{mm}$ );

- spindle speed 8000-10000 rpm

- available cutting feed values: $0.12 ; 0.20 ; 0.32 ; 0.50$ [mm/rot].

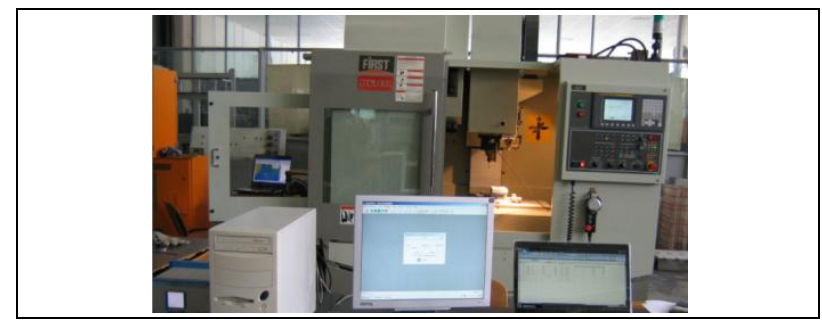

Fig 2. Experimental stand - for force and torque study on machining drilling process

b) Special dynamometric, type 9257B, device for 6 components, Fx, Fy, Fz, Mx, My, Mz. The dynamometer has a great rigidity and consequently a hight natural frequency. Its high resolution enables the smallest dynamic changes in large forces to be measured.

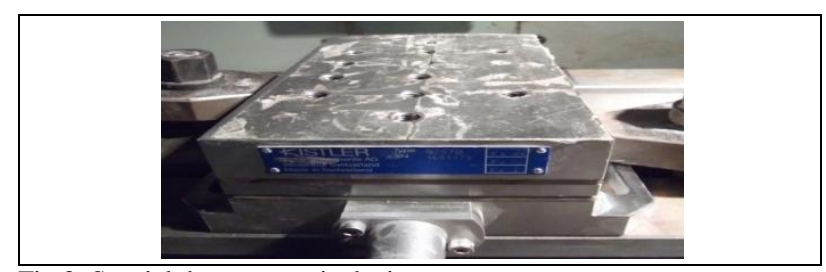

Fig 3. Special dynamometric device

c) Computer Aided Process, special software, amplifier analog-digital

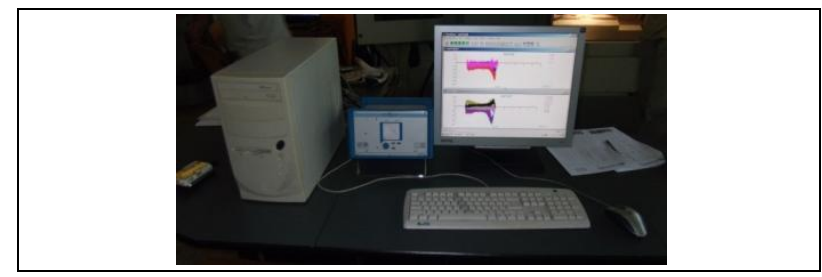

Fig 4. Computer Aided Process, special software

d) Cutting tools for drilling process for polymeric biocomposites

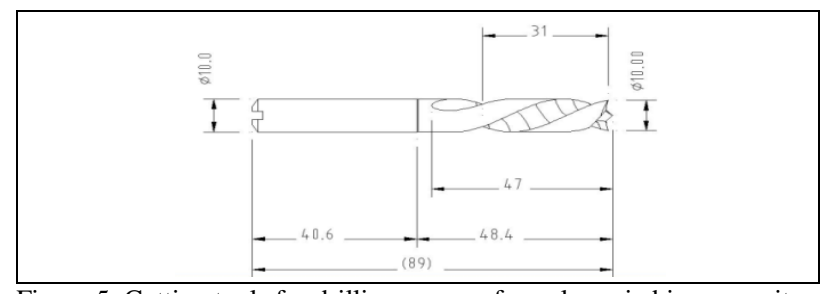

Figure 5. Cutting tools for drilling process for polymeric biocomposites

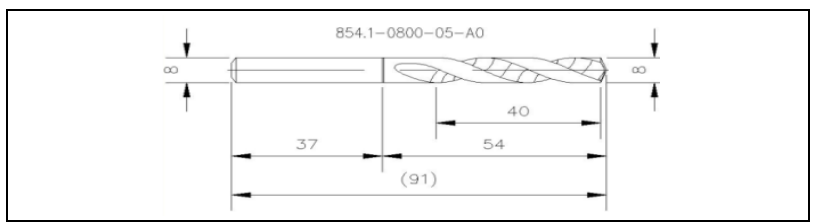

Fig 6. Cutting tools for drilling process for polymeric biocomposites 
e) Studied material: Products made by polymeric biocomposites

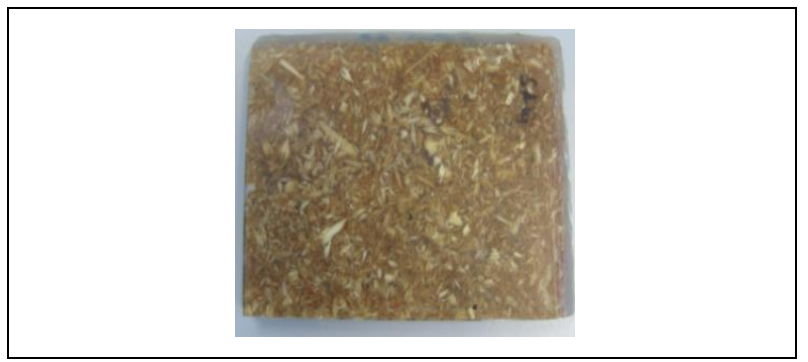

Fig 7. Polymeric biocomposite materials reinforced with wood

Experimental values obtained for the forces $\mathrm{Fz}$ and torque $\mathrm{Mz}$ measurement are shown in the tables 2, and table 3 as follows:

- for the first method, REGS considered, that of solving the four / five linear equations systems - see table 2 ;

- for the second method studied, we use just 3 variables, because the program used was DOE KISS with 3 variables and 2 levels that of experiments design (CCD) and regression analysis - see table 3 .

\begin{tabular}{|c|c|c|c|c|c|c|c|}
\hline \multicolumn{7}{|c|}{$\mathrm{F}_{\mathrm{z}}[\mathrm{N}], \mathrm{M}_{\mathrm{z}}[\mathrm{Nm}]$} \\
\hline $\begin{array}{c}\text { Program } \\
\text { factorial } \\
\text { fracționat } \\
\mathrm{P} 1.2\end{array}$ & $\begin{array}{c}\mathrm{D} \\
{[\mathrm{mm}]}\end{array}$ & $\begin{array}{c}f \\
{[\mathrm{~mm} / \mathrm{rot}]}\end{array}$ & $\begin{array}{c}\mathrm{V}_{\mathrm{c}} \\
{[\mathrm{m} / \mathrm{min}]}\end{array}$ & $\begin{array}{c}\mathrm{F}_{\mathrm{z}} \\
{[\mathrm{N}]}\end{array}$ & $\begin{array}{c}\mathrm{M}_{\mathrm{z}} \\
{[\mathrm{Nm}]}\end{array}$ \\
\hline+1 & -1 & -1 & 10 & 0,02 & 75,36 & 33,10 & 0,52 \\
\hline-1 & +1 & -1 & 8 & 0,15 & 75,36 & 56,12 & 0,61 \\
\hline-1 & -1 & +1 & 8 & 0,02 & 113,04 & 25,12 & 0,39 \\
\hline+1 & +1 & +1 & 10 & 0,15 & 113,04 & 80,77 & 0,88 \\
\hline 0 & 0 & 0 & 8,94 & 0,05 & 92,29 & 42,68 & 0,57 \\
\hline 0 & 0 & 0 & 8,94 & 0,05 & 92,29 & 42,87 & 0,58 \\
\hline
\end{tabular}

$$
\begin{gathered}
F_{z}=f\left(D, f, v_{c}\right), \quad F_{z}=A_{0} \times D^{a 1} \times f^{a 2} \times v_{c}^{a 3} \text {,in } N \\
M_{z}=f\left(D, f . v_{c}\right), M_{z}=A_{0} \times D^{a l} \times f^{a 2} \times v_{c}^{a 3}, \text { in } N m
\end{gathered}
$$

Tab 2. Experimental values obtained for the forces $\mathrm{Fz}$ and torque $\mathrm{Mz}$

\begin{tabular}{|c|c|c|c|c|c|c|}
\hline \multicolumn{7}{|c|}{$\mathrm{F}_{\mathrm{z}}[\mathrm{N}]$} \\
\hline \multicolumn{3}{|c|}{$\begin{array}{ll}\text { Program factorial } \\
\text { fractionat }\end{array}$} & $\begin{array}{c}\mathrm{D} \\
{[\mathrm{mm}]}\end{array}$ & $\begin{array}{c}\mathrm{f} \\
{[\mathrm{mm} / \mathrm{rot}]}\end{array}$ & $\begin{array}{c}\mathrm{V}_{\mathrm{c}} \\
{[\mathrm{m} / \mathrm{min}]}\end{array}$ & $\begin{array}{l}\mathrm{Fz} \\
{[\mathrm{N}]}\end{array}$ \\
\hline-1 & -1 & -1 & 8 & 0.02 & 75.36 & 31,55 \\
\hline-1 & -1 & 1 & 8 & 0.02 & 113.04 & 25,99 \\
\hline-1 & 1 & -1 & 8 & 0.15 & 75.36 & 54,69 \\
\hline-1 & 1 & 1 & 8 & 0.15 & 113.04 & 66,31 \\
\hline 1 & -1 & -1 & 10 & 0.02 & 75.36 & 30,24 \\
\hline 1 & -1 & 1 & 10 & 0.02 & 113.04 & 26,31 \\
\hline 1 & 1 & -1 & 10 & 0.15 & 75.36 & 63,34 \\
\hline 1 & 1 & 1 & 10 & 0.15 & 113.04 & 75,38 \\
\hline
\end{tabular}
for REGS

\begin{tabular}{|c|c|c|c|c|c|c|}
\hline \multicolumn{7}{|c|}{$\mathrm{Mz}[\mathrm{Nm}]$} \\
\hline \multicolumn{2}{|c|}{$\begin{array}{c}\text { Program factorial } \\
\text { fractionat }\end{array}$} & $\begin{array}{c}\mathrm{D} \\
{[\mathrm{mm}]}\end{array}$ & $\begin{array}{c}\mathrm{f} \\
{[\mathrm{mm} / \mathrm{rot}]}\end{array}$ & $\begin{array}{c}\mathrm{v}_{\mathrm{c}} \\
{[\mathrm{m} / \mathrm{min}]}\end{array}$ & $\begin{array}{c}\mathrm{Mz} \\
{[\mathrm{Nm}]}\end{array}$ \\
\hline-1 & -1 & -1 & 8 & 0.02 & 75.36 & 0,42 \\
\hline-1 & -1 & 1 & 8 & 0.02 & 113.04 & 0,5 \\
\hline-1 & 1 & -1 & 8 & 0.15 & 75.36 & 1,28 \\
\hline-1 & 1 & 1 & 8 & 0.15 & 113.04 & 1,33 \\
\hline 1 & -1 & -1 & 10 & 0.02 & 75.36 & 0,39 \\
\hline 1 & -1 & 1 & 10 & 0.02 & 113.04 & 0,41 \\
\hline 1 & 1 & -1 & 10 & 0.15 & 75.36 & 1,25 \\
\hline 1 & 1 & 1 & 10 & 0.15 & 113.04 & 0,31 \\
\hline \multicolumn{7}{|l|}{$M_{z}=a_{0}+a_{1} D+a_{2} f+a_{3 c} v_{c}+a_{12} D f+a_{13} D v_{c}+a_{23} f \nu_{c}+a_{123} D f v_{c}, \hat{\mathrm{in} \mathrm{Nm}} \mathrm{l}$} \\
\hline
\end{tabular}

$\mathrm{Tab}$ 3. Experimental values obtained for the forces $\mathrm{Fz}$ and torque $\mathrm{Mz}$ for DOE KISS

\section{MATHEMATICAL MODELS}

For the first method considered, obtained experimental results were further "processed", in order to solve the four / five linear equations systems, required for models' constants and polytrophic exponents values determination $(\mathrm{C}, \mathrm{x}, \mathrm{y}, \mathrm{z})$, [5].

Knowing that initial dependence relationships were exponential, - relations (7) to (8), there were obtained the mathematical models of force and torque, for machiningdrilling process for products made by polymeric biocomposites materials. [6];

So, in drilling process, there are the final equations - see relations (9) to (10):

$$
F z=A_{0} \times D^{a 1} \times f^{a 2} \times v_{c}^{a 3}=3,926 \times D^{1,441} \times f^{0,427} \times v_{c}^{-0,111}
$$

$M z=A_{0} \times D^{a 1} \times f^{a 2} \times v_{c}^{a 3}=0,029 \times D^{1,479} \times f^{0,247} \times v_{c}^{-0,103}$

Some graphical representations of the obtained mathematical models can be noticed in figure 7 .

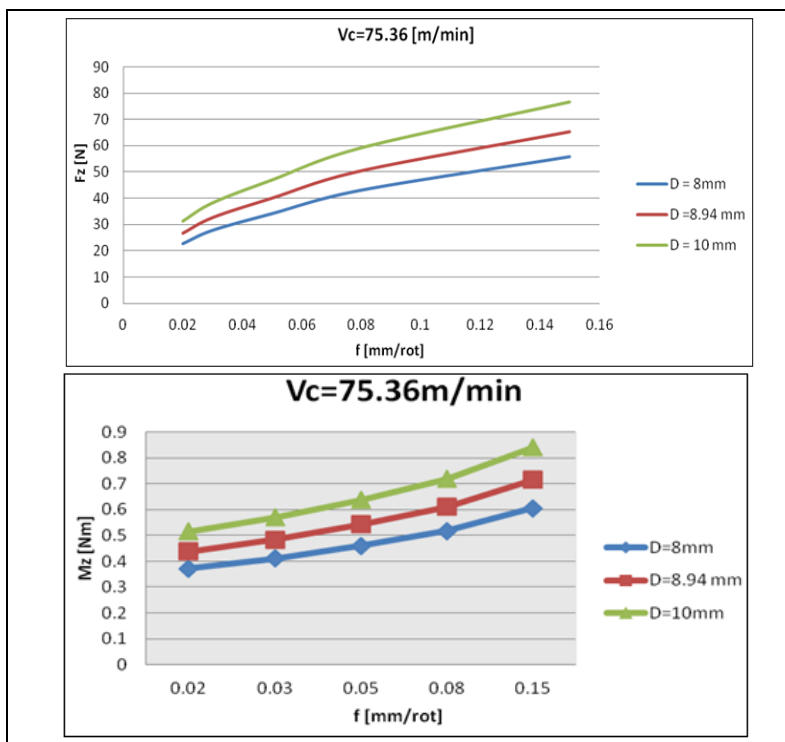

Fig. 8 Graphical representation of $\mathrm{Fz}$ and $\mathrm{Mz}$ - with REGS models relations (9), (10)

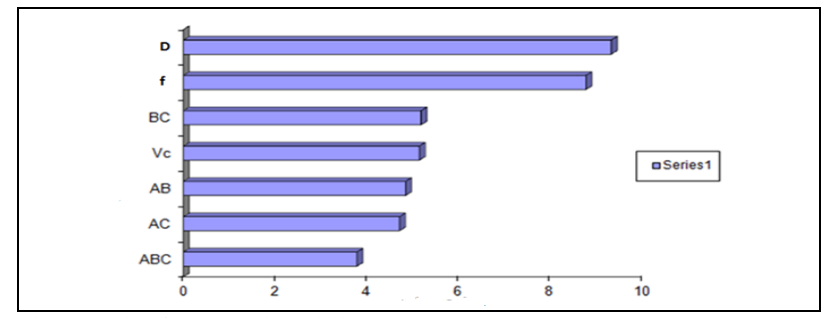

Fig. 9 Axial force Fz, in drilling

As observation, there should be mentioned the fact that these graphs were plotted for the variables with higher influence on force and torque values.

One can notice the fact that relations (9), (10) were obtained by solving classical linear equations system. It means, four / five unknown parameters and, consequently, the need for four / five linear equations 
systems to be solved. So, an "improvement" of the method to obtain mathematical models was considered to be right.

So, for the new sets of experiments, as mentioned before, there have been considered, both the Central Composite Design of experiments and the regression analysis, performed with the special software, DOE KISS.

The only three independent variables studied were the ones that proved (by previously obtained mathematical models) to strongly influence the dependent variable (axial force or torque). All of these are evidenced by table 6.Examples of the DOE KISS software results, are shown in figure 7. So, as result of this method, the obtained mathematical models of force and torque, for machining milling process are the ones mentioned above - see relations (11), (12) :

$$
\begin{aligned}
& F_{z}=13,623+3,328 D+1759,208 f- \\
&-0,018 v_{c}-217,386 D f-0,012 D v_{c}[\mathrm{~N}] \\
&--23,666 f v_{c}+3,101 D f v_{c} \\
& M_{z}=0,256+1.606 D+0.427 f-0.198 v_{c}+[\mathrm{Nm}] \\
&+0.235 D f+0.254 D v_{c}+ \\
&+0.854 f v_{c}+0.125 D f v_{c}
\end{aligned}
$$

Some graphical representations of the obtaining mathematical models can by noticed in figure 8 .

The DOEKISS software also enables to get an image of the marginal means plot, as well as the Pareto chart of coefficients. All of this in order to strengthen the influence of the two independent variables, or their interaction, on the output. Examples are shown in figure 8 and figure 9.

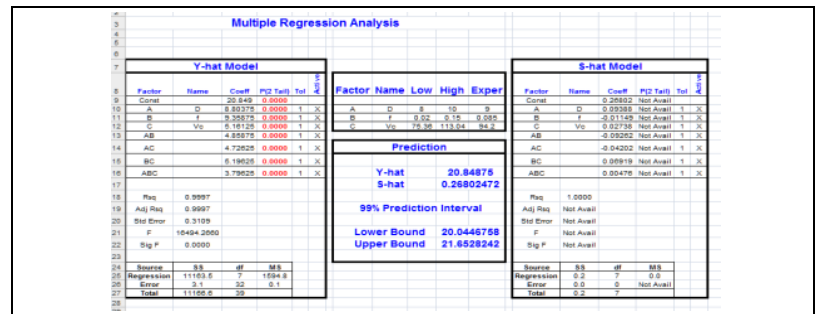

Fig. 10 Axial force, Fz, in drilling

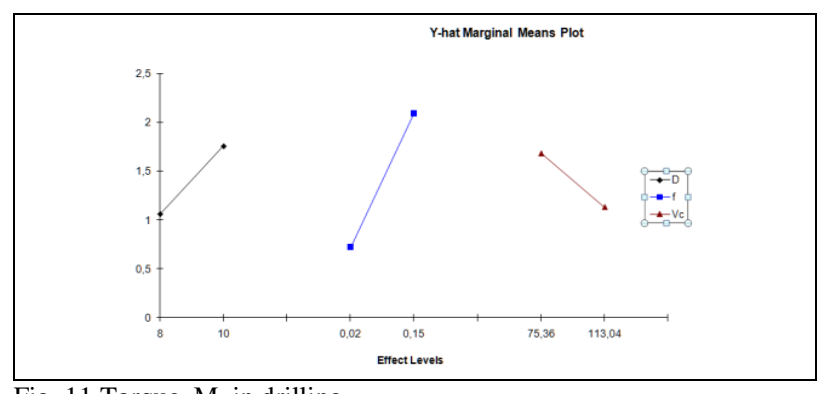

\section{Fig. 11 Torque, M, in drilling}

\section{CONCLUSION}

Polymeric biocomposites characteristics, like high corrosion resistance and impressive good look, involve the use of their parts in more and more versatile and challenging industrial fields. [3];
Polymeric biocomposites parts usually need machining according to the geometric precision required. [7];

This study is about two methods used for determining new adequate mathematical models of the axial force and torque in machining polymeric biocomposites holes.

The first method, consisted in solving the four linear equations systems, required for models' constants and polytrophic exponents values determination $(\mathrm{C}, \mathrm{x}, \mathrm{y}, \mathrm{z})$.

The second method, involved design of experiments (CCD) and regression analysis performed with a special software (DOE KISS).

There were obtained two independent variables polynomial type models and by plotting graphs, it was evidenced their influence, as well as their interaction, on the axial force and torque values.

All the steps carried in order to obtain the new mathematical models can be considered as parts of a "procedure" to be followed / applied for any materials type and different machining procedures, whenever dependence relations of machining parameters are worth to be determined.

Further research involves other process parameters and materials to be studied, as well as the application of obtained models on real time control of the machining processes.

Research presented will lead to widespread application of polymeric biocomposites in automotive and aerospace industry.

\section{REFERENCES}

[1] OPRAN Constantin; DOBRESCU Tiberiu;(2011); Temperature behavior at drilling biocomposite polymeric;Annals of DAAAM for 2011 \& Proceedings of 22 nd International DAAAM Symposium, Volume22, No1, ISSN 1726-9679, DAAAM International; Vienna; Austria

[2] OKSMAN, N. K.; MOHINI, S. (2008). Wood-polymer composites, WoodHEAD Publishing in Materials, CRC, SUA

[3] Pickering, K. (2009). Properties and performance of natural-fiber composites, University of Waikato, New Zealand

[4] TSAI S.W. (2008). Strength \& life of composites, Editor Aeronautics \& Astronautics Stanford University, SUA

[5] MURAR Diana; OPRAN Constantin; BIVOLARU Catalina; (2011); Drilling of biocomposite polymeric products; Annals of DAAAM for 2011 \& Proceedings of 22 nd International DAAAM Symposium, Volume22, No1, ISSN 1726-9679, DAAAM International; Vienna; Austria

[6] OPRAN Constantin; BIVOLARU Catalina; MURAR Diana; VLASE Aurelian; (2010); Research concerning the behavior at impact of the polymeric composite sandwich structures with the simulation of finite element analysis; Academic journal of manufacturing engineering, vol8, issue 1/2010;Romania

[7] FONG T. Jeffrey; (2012) Composites failure criteria and estimation of associated A-and B -basis design allowable; JEC COMPOSITES MAGAZINE, N0 71, March 2012 